\title{
Characteristics and Adaptability Assessment of Commonly Used Ecological Flow Methods in Water Storage and Hydropower Projects, the Case of Chinese River Basins
}

\author{
Lejun Ma ${ }^{1,2,3}$, Huan Wang ${ }^{4,5, *}$, Changjun $\mathrm{Qi}^{1,6}$, Xinnan Zhang ${ }^{1,2,4}$ and Hanwen Zhang ${ }^{1,7}$ \\ 1 Department of Hydrology and Water Resources, Hohai University, Nanjing 210098, China; \\ rivermale@foxmail.com (L.M.); malele000@163.com (C.Q.); zxn@hhu.edu.cn (X.Z.); \\ hanwenzhan05015134@163.com (H.Z.) \\ 2 National Engineering Research Center of Water Resources Efficient Utilization and Engineering Safety, \\ Nanjing 210098, China \\ 3 Nanjing Hohai Technology Company, Nanjing 210098, China \\ 4 State Key Laboratory of Hydrology-Water Resources and Hydraulic Engineering, \\ Nanjing Hydraulic Research Institute, Nanjing 210029, China \\ 5 Hydrology and Water Resources Department, Nanjing Hydraulic Research Institute, Nanjing 210098, China \\ 6 Appraisal Center for Environment \& Engineering, Ministry of Environmental Protection, \\ Beijing 100012, China \\ 7 Shanghai Investigation, Design \& Research Institute Co., Ltd., Shanghai 200335, China \\ * Correspondence: wanghuan@nhri.cn; Tel.: +86-25-8582-8821
}

Received: 8 August 2019; Accepted: 25 September 2019; Published: 29 September 2019

check for updates

\begin{abstract}
The construction and operation of water storage and hydropower projects affects the structure of water ecosystems of downstream rivers, and the establishment of ecological flow in rivers below the water storage and hydropower projects has significant impacts on maintaining the stability of river ecosystems. A database was established based on 2000-2017 environmental impact assessment (EIA) reports on water storage and hydropower projects in China and ecological flow (e-flow) methods, and the three widely used e-flow methods for water storage and hydropower projects in China were identified on the database. Furthermore, an ecological flow satisfaction degree model was used to evaluate the methods using long series of historical hydrological data from the hydrological stations in the Yellow River basin, the Yangtze River basin, and the Liao River basin. The results showed that hydrological methods are the type most often used for water storage and hydropower projects in China, including the Tennant method, the minimum monthly average flow with $90 \%$ guarantee rate method (Mm9M method), and the measured historical minimum daily average flow rate method (MDM method). However, the ecological flow methods selected are not significantly different among different basins, indicating that the selection of ecological flow methods is rather arbitrary, and adaptability analysis is not available. The results of the ecological flow satisfaction model showed that the Tennant method is not suitable for large river basins. The results of this study can provide technical support for establishment and management decisions surrounding ecological flow.
\end{abstract}

Keywords: ecological flow method; water storage and hydropower project; adaptability assessment

\section{Introduction}

A river ecosystem is the unity of material circulation and energy circulation between organisms and their environments and is a continuous system that relies on the hydrological regime $[1,2]$. The socio-economic development of human beings is closely related to rivers. To make more efficient use 
of water resources, humans have built a large number of reservoirs, dams, and water diversion projects on rivers. The World Wildlife Fund (WWF) has surveyed 12 million kilometers of rivers worldwide and assessed their mobility, and their results show that approximately two-thirds of the surveyed rivers have no free flow. In the United States, Europe, and other developed countries, long, free-flowing rivers do not exist; in addition, the rate of decline in the number of freshwater animals and plants is twice the rate of decline in the number of species on land and at sea [3]. According to the latest statistics from the World Commission on Dams, there are a total of 58,400 dams with a height of over $15 \mathrm{~m}$ globally. There are still more than 3700 dams under construction, and the future of free-flowing rivers appears to be bleak [4]. These projects, while meeting economic development needs, including water supply, power generation, shipping, and irrigation, apply great pressure on river ecosystems [5-7].

To evaluate the impacts of water storage and hydropower projects on rivers, researchers analyzed the hydrological changes in 186 dam-building rivers in the United States and found that dams may homogenize the hydrologic variability of rivers [8]. In addition, using the deviation or the variation coefficient and the concentration rate, the degree of hydrological variation in rivers caused by water storage and hydropower projects has been quantitatively analyzed [9]. The reservoir-induced variations in the major hydrological factors and their influence on fish population structure have also been extensively studied in recent years [10-13]. It is generally believed that the construction of reservoir dams has an essential impact on the hydrological situation, which affects the aquatic biological structures after the dam [14-16].

To alleviate the impacts of dam construction and operation on river ecosystems, it is urgently necessary to find a balance between the development and utilization of water resources and ecological protection of rivers. Specifically, human and river ecosystems share the water resources of rivers, which generates the concept of ecological flow (e-flow). The purpose of ecological flow is to consider the requirements for river ecosystems health that would allow human demand to be met [17].

The estimation of ecological water demand in rivers started in the late 1940s in the western United States. After more than 70 years of development, there have been more than 200 ecological flow methods proposed globally, which can be divided into four categories according to their design philosophy: Hydrological methods, hydraulic methods, habitat methods, and holistic analysis methods [18]. Overall, the e-flow methods are relatively mature, and the classification of flow grading for different purposes is relatively precise in developed countries. Moreover, they focus on the minimum flow of rivers, as well as the need to gradually expand from the minimum flow to the level of current needs to maintain the institutional functions of river ecosystems, with particular attention paid to the flow required for spawning migration of in-channel organisms $[19,20]$.

The estimation of ecological flow started in China in the 1970s, and after more than 40 years of development, a large number of research results have emerged. However, most of these results are based on mature methods and only some improvements were made to consider the particularities of rivers in China. For example, by modifying the 7Q10 method (defined as seven consecutive days with low flow based on a return period of 10 years), several ecological flow methods suitable for China are proposed: The multi-year average of the mean monthly dry flow, the minimum monthly mean flow method, and the minimum monthly average flow with a $90 \%$ guaranteed rate method [21]. Using a case study and validating with the Tennant method (developed in Montana, is based on a percentage of the mean annual flow (MAF), which takes $10 \%$ of the MAF as the minimum e-flow), several scholars proposed a monthly (year) guarantee rate-setting method to calculate the water demand under different conditions, which is more suitable for seasonal rivers, such as those that occur in the Huang-Huai-Hai Plain [22]. To address the relatively current water pollution in China, researchers have proposed a variety of e-flow calculation methods that target water quality, such as the environmental function setting method, which is based on the river water quality protection standard and the pollutant discharge concentration and can be used to calculate the amount of water needed to meet environmental functions (i.e., river dilution and self-purification) [23,24]. The physical habitat simulation model that combines the Delft 3D hydraulics model and habitat model also has been used to calculate the ecological water requirement in the Yangtze 
River basin $[25,26]$. In recent years, government management departments have grown increasingly concerned about ecological water demand. The national scientific and technological research projects in the Tenth Five Year Plan focused on the ecological restoration of the Liaohe River basin; based on the present conditions of the Liaohe River basin, the second-level water ecological subregion of the Liaohe River basin was constructed. In 2009, major national science and technology projects focused on the ecological environment restoration of the Weihe River basin. The national scientific and technological research projects in the Eleventh Five Year Plan completed and improved a number of different regions, different types and different periods, and completed an ecological water demand study at the river basin scale in China.

In general, recent studies have focused on constructing calculation methods for specific river segments. However, the concept and connotations of ecological flow have not been unified, the focuses of these calculation methods are not the same, and the scope of their application also varies. It is difficult to form a set of highly adaptive calculation systems.

The development of ecological flow for water storage and hydropower projects in China has been relatively slow. In the beginning, the definition of ecological flow was not unified, and there were many related concepts, such as the minimum flow and the in-stream flow. In addition, there were also no official recommended methods. Before 2000, environmental impact assessment (EIA) of water storage and hydropower projects did not mention the demand for ecological flow. Until 2006, the 'Technical Guide for Environmental Impact Assessment of River Ecological Flow, Cold Water, and Fish Passage Facilities for Water Conservation Construction Projects (Trial) EIA Letter (2006) No.4' was issued by the State Environmental Protection Administration, which defined the concepts and methods of ecological flow in EIA for the first time, recommending 10\% of the average annual natural runoff as the minimum flow. However, this "Guideline" does not explicitly propose the appropriate calculation methods and the usage criteria for each method, and results from the adaptability assessment of the relevant ecological flow calculation methods are few [27].

This paper attempts to address the aforementioned issues by examination of existing EIA reports from 2000 to 2017 and determining the common methods used for ecological flow in China's water storage and hydropower projects. Moreover, we constructed a model to assess the degree of ecological flow satisfaction to emphasize the applicability of commonly used ecological flow methods in a water storage and hydropower projects in China. The research results can provide technical support for the establishment of ecological flow and for management decision-making, which is of great significance for protecting river ecosystem after damming.

\section{Materials and Methods}

\subsection{Data}

\subsubsection{EIA 2000-2017 Database}

We constructed a database to restore the 206 EIA reports of water storage and hydropower projects during the period 2000-2017. The analyzed projects had passed the EIAs, which were downloaded from the EIA Center website.

The EIA is an administrative support procedure used by authorities to identify, describe, and assess the environmental impacts of a project. The results reflect the general opinions of the government, experts, and scholars. From the EIA, we can obtain the current status of ecological flow methods used in China's water storage and hydropower projects.

Ecological flow is not only a scientific issue but also a management issue. China's regulations did not mandate the rule of ecological flow from water storage and hydropower projects until 2006. Therefore, the analysis in this paper emphasized that 2006 was an important time node. 


\subsubsection{Hydrological Data}

The Chinese Hydrological yearbook (The Red Book) is compiled by the hydrology department based on actual monitoring data. The data have passed through reliability, consistency, and representativeness tests, which were analyzed by hydrographic officers.

Considering the impact of water storage and hydropower projects and human activities on the current environment, the Red Book of each hydrological yearbook form 1950 to 1986 were extracted to analyze the adaptability of the ecological flow calculation method.

\subsection{Assessment Model}

There are more than 200 types of methods for ecological flow worldwide, and it is evidenced that results from different e-flow methods are different. Thus, it is important to choose an appropriate ecological flow method for determining the ecological flow of rivers. This paper uses the ecological flow satisfaction index to construct an evaluation model to initially evaluate the adaptation of the widely used ecological flow methods in China.

The ecological flow satisfaction degree is a commonly used method to assess the ecological water demand, which is usually the ratio of the series length of the actual runoff of the river course that is greater than the ecological water demand threshold to the total series length [28]. The assessment of the e-flow satisfaction degree usually uses the monthly average flow ecological water conservation rate to reflect the current river ecosystem water shortages; the assessment results can result in ecosystem water shortages $[29,30]$.

$$
\begin{gathered}
P_{i}=\frac{D_{i}}{12}=\frac{\sum_{1}^{12} \operatorname{sgn}\left(Q_{i j}-E_{i j}\right)}{12} \times 100 \%, \\
\text { where } \operatorname{Sgn}\left(Q_{i j}-E_{i j}\right)=\left\{\begin{array}{c}
1, Q_{i j}-E_{i j} \geq 0 \\
0, Q_{i j}-E_{i j}<0
\end{array}\right.
\end{gathered}
$$

where $P_{i}$ is the satisfaction degree of the ecological water requirement in the $i$ th year, $D_{i}$ is the number of months that the ecological water requirement was met in the $i$ th year, $Q_{i j}$ is the average flow at the $j$ th month in the $i$ th year, and $E_{i j}$ is the e-flow of the $j$ th month in the $i$ th year.

From Equation (1), it can reflect the degree of the actual runoff meets the e-flow demand. However, Equation (1) cannot reflect a certain satisfaction degree of e-flow, especially in EIAs of water storage and hydropower projects in China. For example, if the e-flow is smaller than the measured minimum flow in the river, the result of Equation (1) is 100\%, and this result is unreasonable. Moreover, if the e-flow is smaller than the minimum e-flow requirement from the "Guideline", which means $E_{i j}$ is less than $10 \%$ of the multiple average annual flow (MAF), the results of Equation (1) still do not reflect this phenomenon.

Therefore, we add the above restrictions on the basis of Equation (1), and an e-flow satisfactoriness model is proposed for the preliminary evaluation of the adaptability of e-flow methods for water storage and hydropower projects in China.

$$
\begin{gathered}
P_{i}=\frac{D_{i}}{12}=\frac{\sum_{1}^{12} \operatorname{sgn}\left(Q_{i j}-E_{i j}\right)}{12} \times 100 \%, \\
\text { where } \operatorname{Sgn}\left(Q_{i j}-E_{i j}\right)=\left\{\begin{array}{c}
1, Q_{i j}-E_{i j} \geq 0 \text { and } Q_{\min }-E_{i j} \geq 0 \\
0, Q_{i j}-E_{i j}<0 \text { and } Q_{\min }-E_{i j} \geq 0 \\
0, Q_{\min }-E_{i j}<0 \text { or } E_{i j} \geq 0.1 \times Q_{a v g}
\end{array},\right.
\end{gathered}
$$

where $P_{i}$ is the satisfaction degree of ecological water requirement in the $i$ th year, $D_{i}$ is the number of months that the ecological water requirement met in the $i$ th year, $Q_{i j}$ is the average flow at the $j$ th month in the $i$ th year, $E_{i j}$ is the e-flow of the $j$ th month in the $i$ th year, $Q_{\min }$ is the smallest monthly mean flow measured in the $i$ th year, and $Q_{a v g}$ is the annual average flow for 36 years from 1950 to 1986. 


\subsection{Study Area}

China has a vast territory and a relatively large geographical span. There is typically greater precipitation in southern China than in northern China, and the ecosystem structure of different regions is quite different, showing prominent seasonal and regional characteristics [30]. The choice of an appropriate calculation method for determining the different annual and seasonal e-flows in different regions of China is important for determining the spatial distribution of e-flow in China.

In this paper, we chose the 6 representative hydrological stations in the first level or second level basins in China to assess the widely used e-flow methods (Figure 1), which are the Han River basin (Ankang Station, AK), Yangtze River basin (Pingshan Station, PS; Xiaodeshi Station, XDS; Kangding Station, KD), Yellow River basin (Anningdu Station, AND), Songhua River basin (Songhuajiang Station, SHJ).

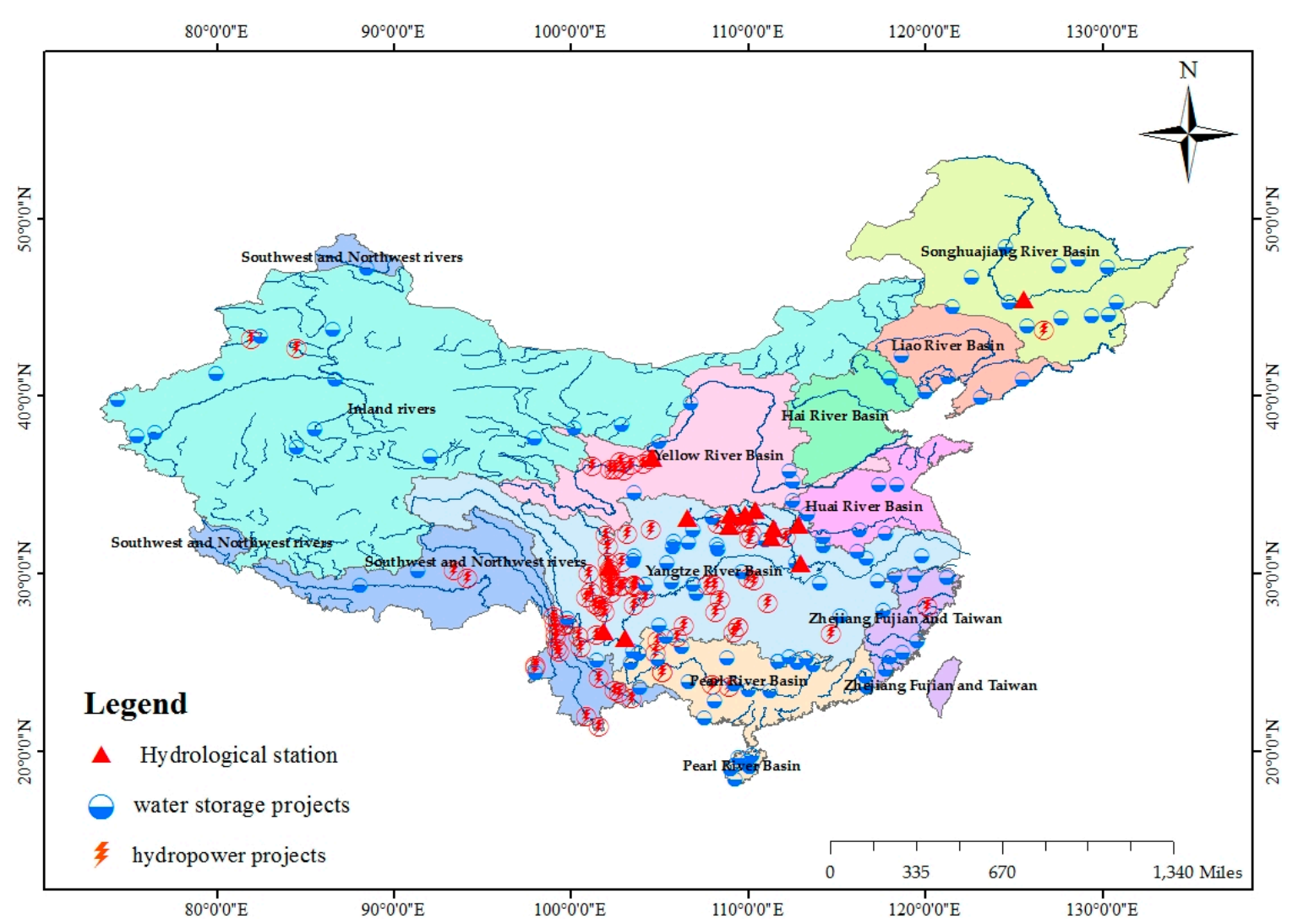

Figure 1. Distribution of water storage and hydropower projects, and hydrological stations of this study in China.

In addition, the differences in the calculation methods among different river sections in the same basin were also analyzed. We selected four hydrological stations in different parts of the Han River basin to analyze the adaptability of the calculation method of e-flow in different parts of the Han River basin. Such as the Wuhou town (WHZ) station upstream of the mainstream, the Huangjiagang station (HJG) and Hongiiadu (HJD) station in the middle stream, and the Xincheng (XC) station downstream of the mainstream, as well as 5 stations in the tributaries, including the Zijingguan (ZJG) station at the Danjiang River, the Nanguangping (NKP) Station in the Jiahe River, the Tanghe (TH) Station in the Tang River, the Kaifengyu (KFY) Station in the Nanhe River, and the Chaiping (CP) Station in Xunhe River (Figure 2). 


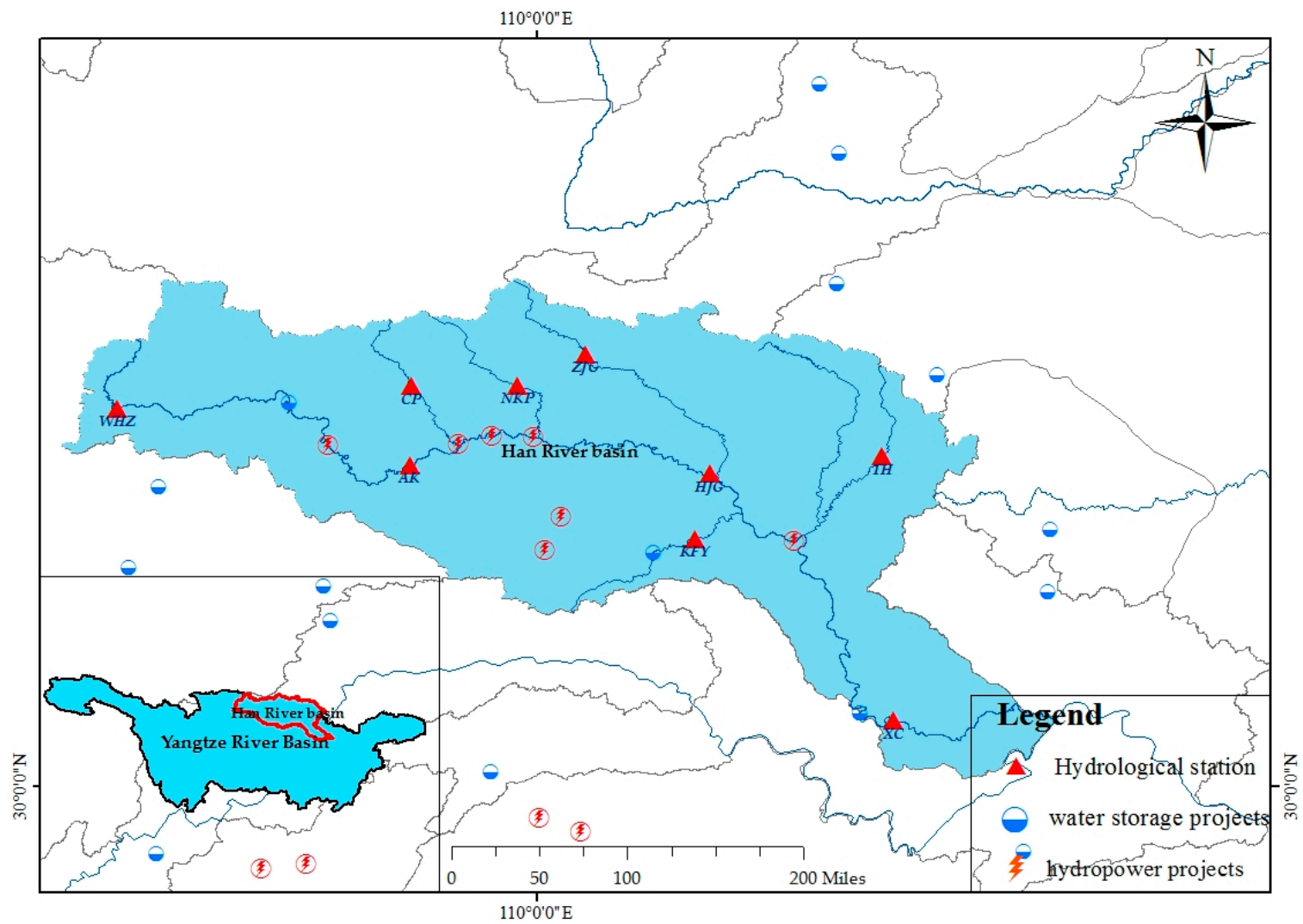

Figure 2. Delivery of water storage and hydropower projects, and typical hydrological stations in the Han River basin.

\section{Results}

\subsection{Practice of Ecological Flow Methods}

\subsubsection{Construction of Water Storage and Hydropower Projects}

Among the 206 water storage and hydropower projects, 75 were constructed before 2006 (37 water storage projects and 38 hydropower projects), and 131 were built after 2006, of which 75 were water storage projects, whereas 56 were hydropower projects.

A total of 133 projects calculated the e-flow ( 59 were water storage projects and 74 were hydropower projects), and 73 projects did not calculate the e-flow (53 water storage projects and 20 hydropower projects) (Table 1).

Table 1. Characteristic parameters of the water storage and hydropower projects.

\begin{tabular}{cccc}
\hline Project & Water Storage Project & Hydropower Project & Total \\
\hline Constructed before 2006 & 37 & 38 & 75 \\
Constructed after 2006 & 75 & 56 & 131 \\
Total & 112 & 94 & 206 \\
\hline E-flow not calculated & 53 & 20 & 73 \\
E-flow calculated & 59 & 74 & 133 \\
Total & 112 & 94 & 206 \\
\hline Constructed before 2006 & 3 & 27 & 30 \\
with e-flow calculated & & & 103 \\
Constructed after 2006 & 56 & 47 & 133 \\
with e-flow calculated & 59 & 74 &
\end{tabular}


Among the 133 projects, 30 were constructed before 2006 (3 water storage projects and 27 hydropower projects), and 103 were built after 2006, of which 56 were water storage projects and 47 hydropower projects.

\subsubsection{Use of Ecological Flow Methodology}

Among the 133 water storage and hydropower projects discussed above, the hydrological method is the most widely used method, accounting for 171 uses. The hydraulic method and habitat simulation methods were both used approximately 20 times. The comprehensive analysis method was rarely used in China, and only one case was found in this study. Several water storage and hydropower projects consider the landscape water requirements, which occurred a total of 25 times (Figure 3a).

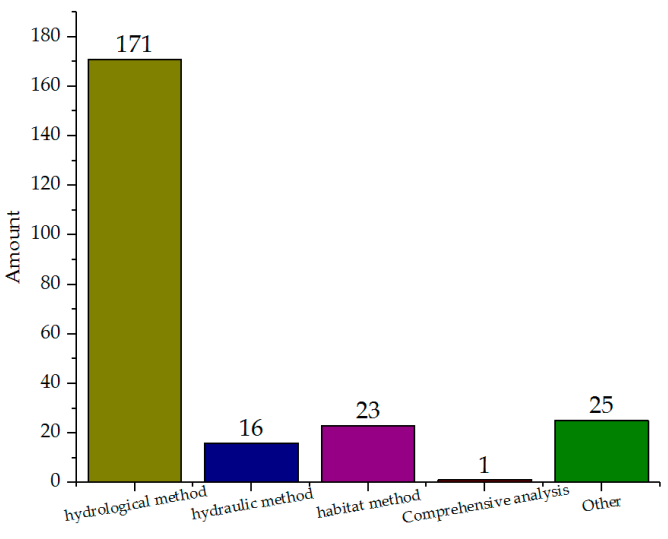

(a)

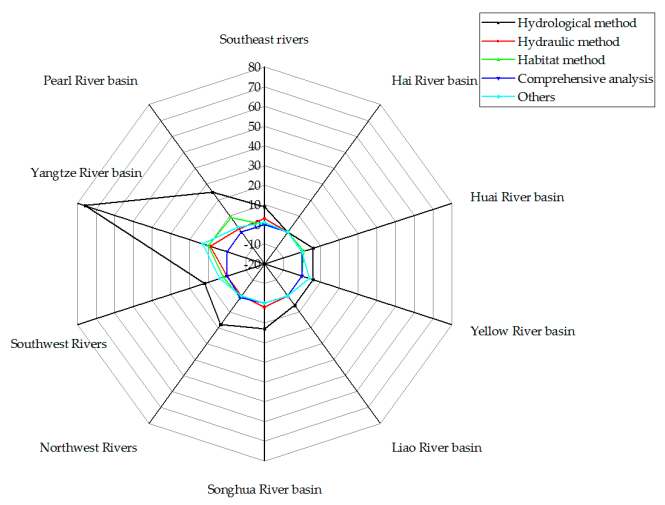

(b)

Figure 3. Current status of ecological flow (e-flow) methods applied in water storage and hydropower projects, China. (a) Frequency of use of e-flow methods for water storage and hydropower projects; (b) application of e-flow methods in different basins for water storage and hydropower projects.

We also analyzed the conditions of e-flow methods in different watersheds. Hydrological methods were not used in the Hai River basin but were used in other basins. The hydraulic method was rarely used in China. It was used primarily in the south-eastern rivers (three times), the Yangtze River basin (nine times), the Songhua River, and the Pearl River basin (two times) and was not used in other basins. The use of the habitat simulation method is mainly in the Yangtze River basin (10 times), and the comprehensive analysis method was only used once in a river basin in north-western China and not in any other basins (Figure 3b).

Among the ecological methods, we summarized the three most widely used e-flow methods, which are all hydrological methods, including the Tennant method, the minimum monthly average flow with a $90 \%$ guarantee rate method (Mm9M), and the minimum daily average flow method (MDM) (Table 2).

The Tennant method is the most commonly used in case studies (84 times). The Tennant method was first reported by Tennant in 1976, who established the relationship among aquatic organisms, the river landscape, recreation and river discharge by analysing cross-sectional data of 11 rivers in the United States, suggesting that $10 \%$ of the MAF is the minimum e-flow. At present, the Tennant method is the most widespread hydrological method used worldwide and is the second most widely applied e-flow method in North America. It is also one of the recommended methods of the "Guideline".

The 7Q10 method is a hydrological method defined as low flow based on a return period of 10 years spanning seven consecutive days. The 7Q10 method uses hydrological parameters and water quality factors (river self-purification capacity) to calculate ecological water demand.

The Mm9M method is the second most frequently used method, which is improved from the 7Q10 method and has been used 40 times in different projects and selected basins. Due to the high requirements of the 7Q10 method for pollutant discharge, the "Technical Principles and Methods 
for Establishing Local Water Pollution Discharge Standards" (GB3839-1983) ruled that the minimum monthly average flow with a $90 \%$ guarantee rate should be used as the minimum e-flow [31].

The MDM method is the third most widely used method in EIAs of water storage and hydropower projects and was used 19 times in our case study. The MDM method is a hydrological method applied to watersheds in China, which is based on the Tennant method. It usually takes the minimum daily average flow measured over many years as the minimum e-flow.

Table 2. Application of e-flow methods for water storage and hydropower projects since 2000.

\begin{tabular}{cc}
\hline Calculation Method & Amount \\
\hline Hydrological methods & $\mathbf{1 7 1}$ \\
\hline Flow duration curve method & 8 \\
Tennant & 84 \\
$5 \%$ average annual flow & 8 \\
Minimum monthly average flow method & 9 \\
Minimum daily average flow method (MDM ) & 19 \\
Minimum monthly average flow with 90\% guarantee rate method (Mm9M) & 40 \\
Others & 3 \\
\hline Hydraulic methods & $\mathbf{1 6}$ \\
\hline Reted Perimeter & 9 \\
\hline Habitat methods & 7 \\
\hline Biological simulation & $\mathbf{2 3}$ \\
\hline Eco-hydraulic method & 8 \\
\hline Comprehensive analysis & 15 \\
\hline Others & $\mathbf{1}$ \\
\hline E.g., shipping, landscape water usage & $\mathbf{2 5}$ \\
Stable water quality method & 24 \\
\hline
\end{tabular}

Note: Considering the difference between e-flow methods, multiple e-flow methods were occasionally used in a single project to determine the e-flow during the process of environmental impact assessment (EIA), which is the main reason that the number of e-flow methods exceeds the number of projects.

\subsection{Ecological Flow Satisfaction Degree}

We calculated the e-flow satisfaction degree of each method by the assessment model, which are the Tennant method, the MDM method, and the Mm9M method.

We first calculated the e-flow satisfaction degree of different methods at the control stations of each major basins. The results indicated the Tennant method was widely used to calculate the e-flow of water storage and hydropower projects in various basins, its ecological satisfaction degree at all of the stations were zero. In contrast, the MDM method performed well in all control stations and all of its e-flow satisfaction degrees were $100 \%$. In contrast, the results of the Mm9M method varied, and the results at the six stations were only approximately $50 \%$ (Figure 4 ).

The adaptability of the ecological methods in different parts of one basin also varies. Based on the results from the nine control stations in Han River basin (Figure 5), the results showed that the e-flow satisfaction degrees calculated from the Mm9M method in Han River basin were generally not high, resulting in e-flow satisfaction degrees of $20-100 \%$ (Figure 6).

The Tennant method performed differently between the mainstream river and the tributaries. The e-flow satisfaction degrees at the HJG, XC, and AK stations were zero, which are on the main channel of Han River basin. The results at the upstream stream control station WHZ was approximately $80 \%$, and the tributary stations (ZJG, NKP, and TH) exhibited a value of $100 \%$, although the ecological satisfaction degrees at the other tributary stations (KFY and $\mathrm{CP}$ ) were zero.

Although the MDM method performed well, the results were also zero at ZJG, WHZ, and TH and $100 \%$ at the other stations. 

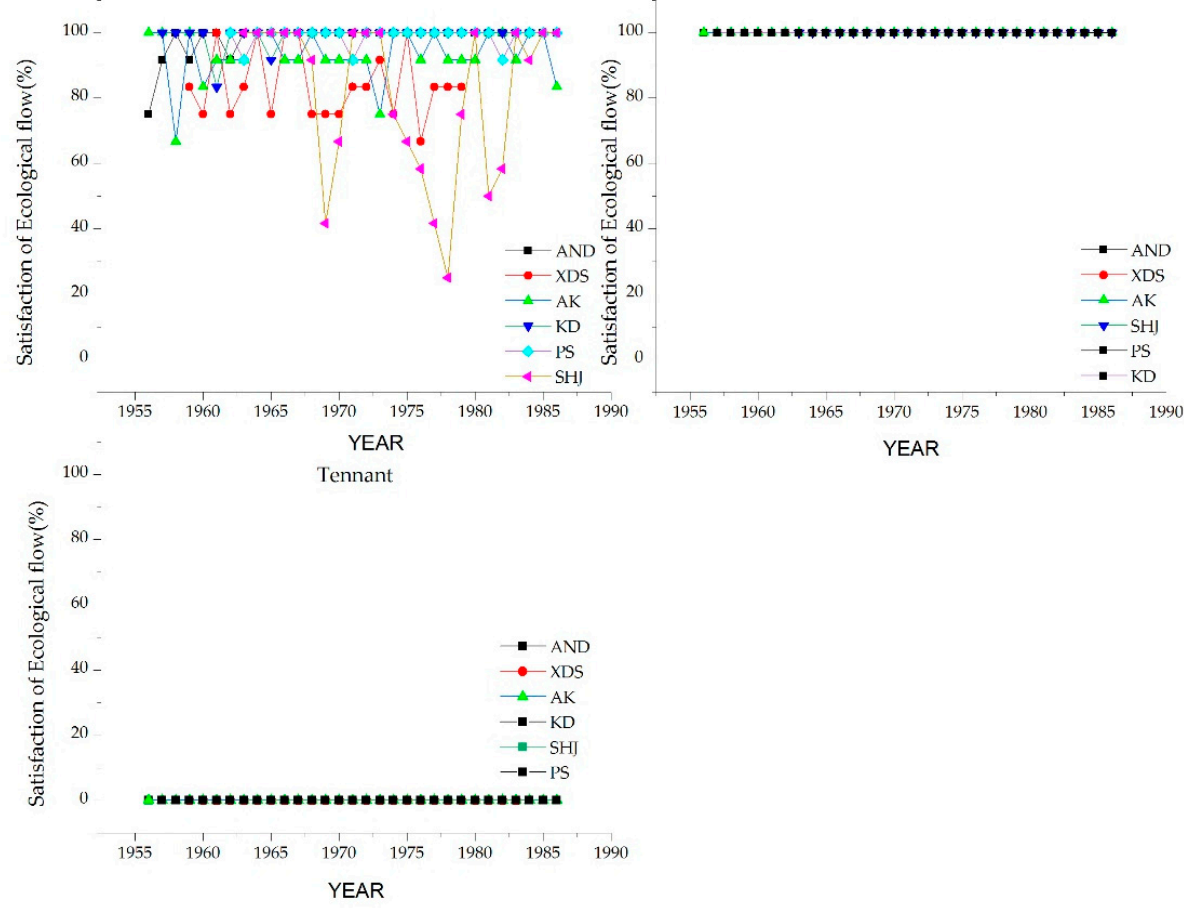

Figure 4. The assessment model results of different methods for the control hydrologic station in the mainstream section of the river basin.
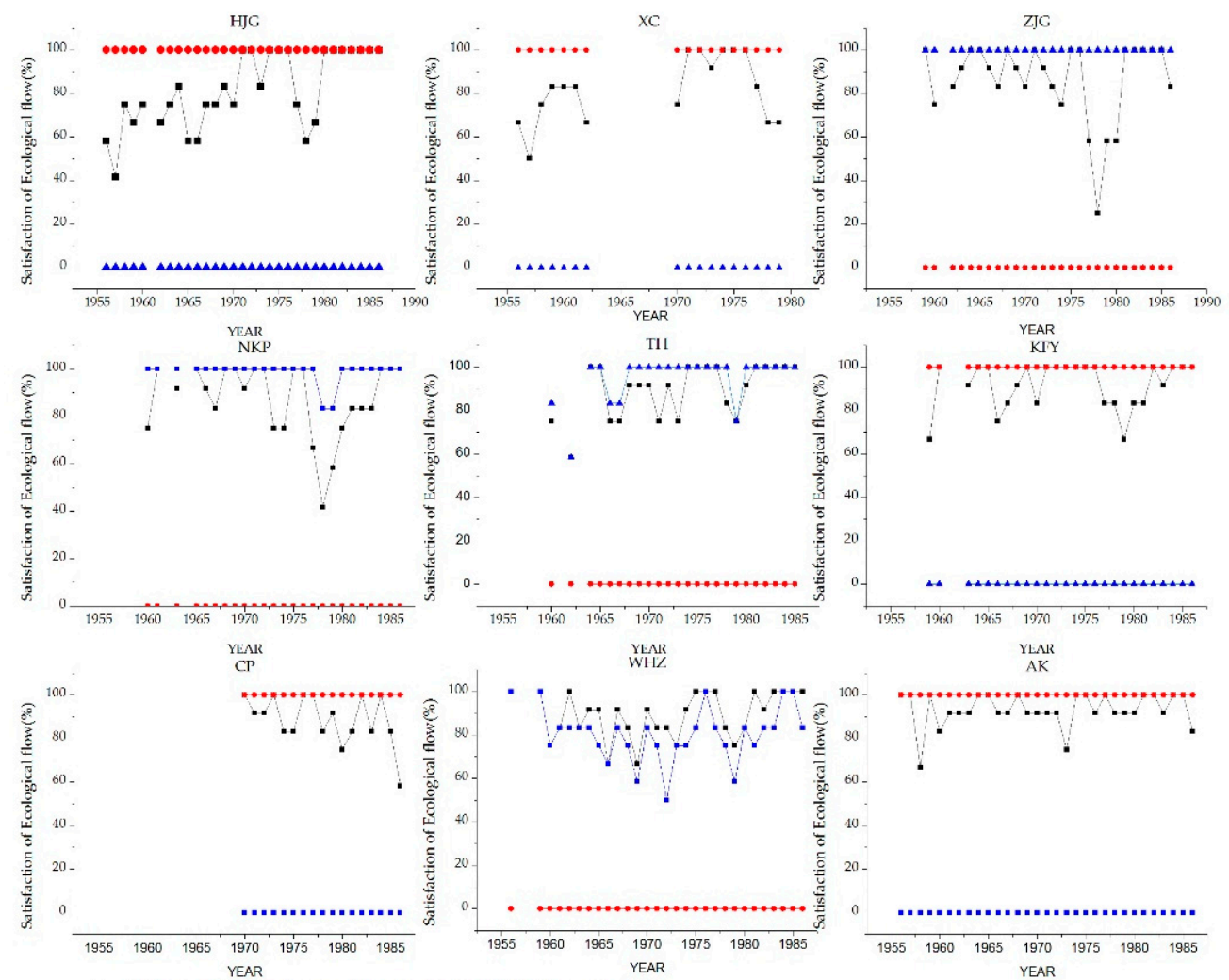

- Minimum Monthly Average lilow Method with $90 \%$ Guarantee Rate

- Minimum daily average flow method

$\triangle$ Tennant

Figure 5. Ecological satisfaction degrees of different e-flow methods at hydrological stations in the Han River basin. 


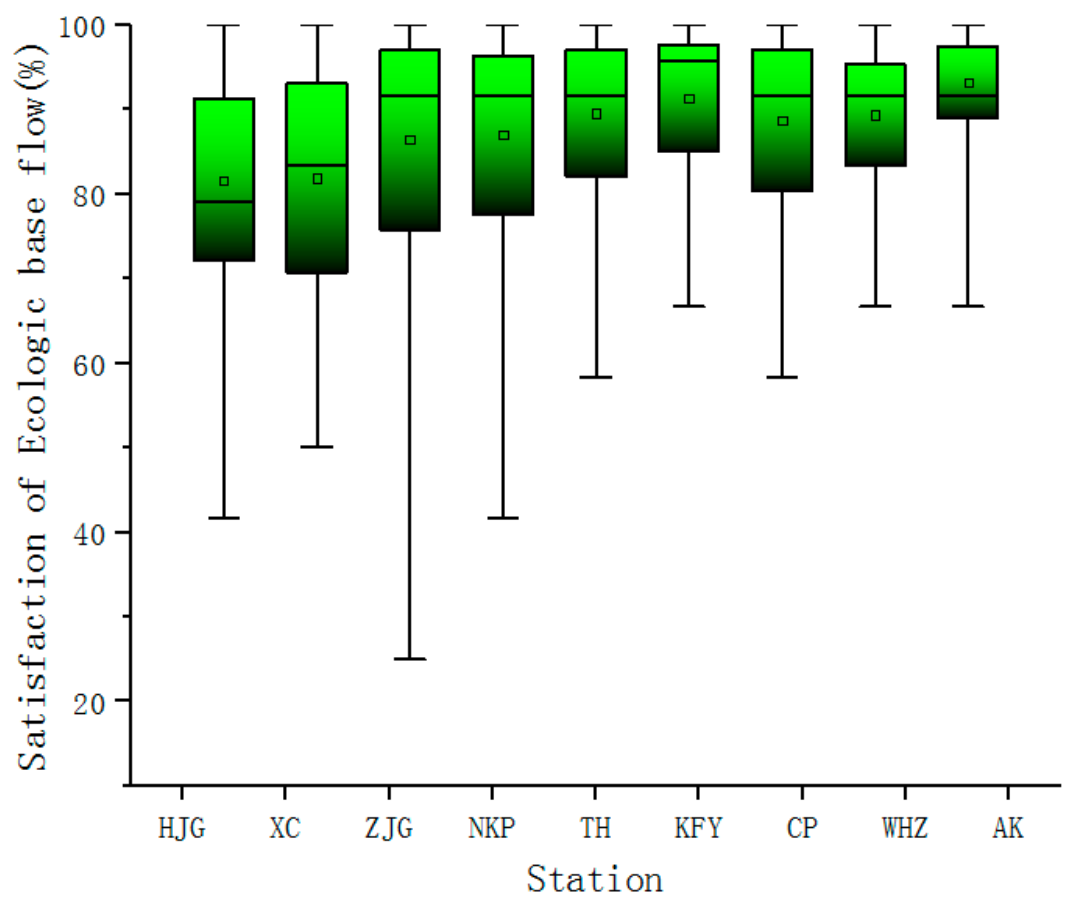

Figure 6. Distribution of ecological satisfaction degrees by the minimum monthly average flow with $90 \%$ guarantee rate method (Mm9M) method in the Han River basin.

\section{Discussion}

Determining the e-flow for water storage and hydropower projects is significant for river ecosystem. Therefore, the Ministry of Environmental Protection issued a "Guideline" in 2006, which clear stated the minimum standards for e-flows from water conservancy and hydropower projects. After more than ten years of development, we found that the "Guideline" played an essential role in promoting the discharge of e-flow, and the percentage of projects that disseminated e-flow increased from 30/75 to $103 / 131$. However, there are still several problems in management, such as the lack of theoretical basis for choosing the calculation methods of e-flow, and lack of a rationality analysis used for e-flow methods.

\subsection{Practice of Ecological Flow Methods}

Ecosystems have well-defined regional characteristics [32], and several scholars have proposed dividing China into five major regions based on the present regional conditions [33,34].

Different ecological flow methodologies should be and are used in different areas and for different purposes, which range from global water resources planning to detailed planning for managed dam releases. The results of this paper show that the selection of methods within the study area does not differ much within China; e-flow in major river basins has been mainly calculated using hydrological methods, including the Tennant method, the Mm9M method, and the MDM method. Other methods, such as habitat simulation, hydraulics, and comprehensive analyses have been infrequently used; these results are similar to those of other papers $[35,36]$. This shows that the choice of e-flow methods in China is somewhat random. By comprehensively analyzing the aforementioned results, we believe that the main reasons for the current situation are as follows:

1. China did not explicitly clarify the demand for e-flow in the EIA of water storage and hydropower projects before 2006, and the regulations did not expressly clarify the calculation method guidelines; therefore, the selection of the e-flow calculation methods in the EIA of water storage and hydropower projects relied on the subjective judgment by designers [37]; 
2. The hydrological method is the most widely used in the world because of its simple use and low threshold. Furthermore, China's water storage and hydropower projects are mostly located in remote mountainous areas in the southwestern region $[35,36,38]$ and the data in this area are mostly concentrated in river flow monitoring, while other basic data monitoring systems are lacking, which limits the application and popularization of different methods.

The hydraulic and habitat simulation methods have been commonly used in the Yangtze River basin and the Pearl River basin, where many water storage and hydropower projects have occurred. However, economic capacity is positively correlated with the abundance of primary hydrological data, and those basins represented one of the most developed regions in China, which can support the data demand of the various methods [39].

Relative to the hydraulic method, the habitat simulation method, which considers the biological and ecological water requirements, is relatively mature and has a solid theoretical basis. It is more suitable for the analysis of e-flow on the river scale, and it is currently thought to be able to quantify e-flow and consider ecological factors, making it a relatively credible assessment method [40,41]. However, this method has particular data requirements. The status quo of the current hydraulic fundamental data in China limits the extensive use of this method; in the future, China should vigorously strengthen hydraulic data to meet the data demand of various methods [42].

The comprehensive analysis method rarely appeared in our statistical results. This method studies the relationship among flow, sediment transport, riverbed shape, and riparian community based on expert advice from the entire ecosystem so that the recommended river flow can simultaneously satisfy multiple functions such as biological protection, habitat maintenance, sediment deposition, pollution control, and landscape maintenance. This method has a relatively high demand for data and emphasizes the river's natural properties. However, it is difficult to restore waterways to pristine conditions under the impact of a dam; thus, the adaptability of this method in the ecological restoration of post-dammed rivers is low [43].

3. More studies on the resilience of e-flow methods for local areas are needed. There are few studies on the advantages and disadvantages of hydrological methods for small watersheds, which results in a lack of theoretical basis for the application of calculation methods;

4. There is a lack of new methods or techniques for determining e-flow for different conditions. We believe that there should be specific methods for assessing e-flow problems, which distinguish spatial and temporal ecological problems or the planning purposes;

5. E-flow conflicts with power generation efficiency; therefore, water storage and hydropower project managers usually chose the minimum standard specified in the "Guideline" to pass the environmental impact assessment. That is, the minimum value in the Tennant method and the rationality of the established results have not been deeply analyzed.

In the statistical process, we found that the French Rural method (defined as $5 \%$ of the AMF) was used eight times; this result surprised us because this contradicts the lower limit of the e-flow specified in the guidelines, which has no reference significance in the calculation of the e-flow of water storage and hydropower projects in China. However, this result indicates several problems in the computation and supervision of current e-flow calculations.

\subsection{Assessment of Ecological Flow Methods}

Hydrological methods are widely applied in China, yet the spatial and temporal variability of the e-flow criteria have been frequently questioned because these method usually have an absolute value for a certain year [44]. Using the normal fish spawning period (April to September) as an example, the hydrological regime of rivers below a dam calculated by these methods does not change, even during the period of fish spawning, resulting in a single hydrological regime and a single biological environment in the channel. This also explains the gradual shrinking of the population of Chinese sturgeon in the Yangtze River basin [45]. 
The Tennant method's e-flow satisfaction degree results are usually 0 in most main streams of rivers, which demonstrates that the calculated results are lower than the historical measured minimum flow and indicates that the Tennant method may not be suitable for water storage and hydropower projects in large river basins. This conclusion is inconsistent with the general belief that the Tennant method applies to rivers and perennial rivers $[46,47]$. The reason may be that the Tennant method is a well-known method in the United States and the world, and it may be more suitable for the actual situation of rivers in the United States and is not as adaptable to research in China. In addition, the management of e-flow is different in rivers and damming rivers according to the policy [48]. Therefore, an adaptation study of this method in downstream areas of China's water storage and hydropower projects should be carried out.

The MDM method is mainly based on the minimums of historical daily flow records, which are improved from the Tennant method for water storage and hydropower projects in China; this method performs well for large rivers but is not suitable for rivers with low flow, such as the tributary of the Han River basin. Rivers exhibiting the "cut-off" phenomenon, with minimum hydrological flow of 0 , are most susceptible to errors when using this method. The Mm9M method's results are generally large, which indicate the ecological satisfaction rate is usually low in the mainstreams and tributary channels of rivers and that e-flow will cause waste of water resources. Thus, adaptive analytical research related to this method is sorely needed.

In this paper, we did not analyze the adaptability of various e-flow methods in different water use periods (time), nor did we consider the e-flow requirements of different organisms in the river. Therefore, the results in this study are only the initial screening of the adaptability of ecological flow calculations in China. In the future, a calculation framework based on time and space needs to be established to refine the calculation rules of e-flow and provide technical support for the ecological protection of river segments.

\section{Conclusions}

The calculation and establishment of e-flow in rivers affected by water storage and hydropower projects have significant impacts on maintaining the stability of river ecosystems. This paper collected 206 EIA reports for water storage and hydropower projects in China after the year 2000 and summarized the practice characteristics and application of e-flow methods in China and in first-level basin. Furthermore, the applicability of commonly used calculation methods in China was also discussed. The results of this study can provide technical support for establishment and management decisions surrounding ecological effects.

In summary, after implementing e-flow management, a variety of e-flow calculation methods are synthetically used, which greatly improve the application of e-flow measures in China. The most commonly used methods of e-flow are hydrological methods, including the Tennant method, the Mm9M method, and the MDM method.

Although e-flow management has played a positive role in the protection of river ecosystems, a series of problems remain, such as the blind calculation of e-flow, un-regionalization selection of e-flow methods, the unreasonable calculation of e-flow rates, and the lack of reasonable analysis of e-flow method. Therefore, in the future, the framework of e-flow management should determine the relationship regional ecological method model to optimize the e-flow method, and the ecological adaptability of the regulatory system; these changes will provide basic research support for the development of e-flow management policies.

Author Contributions: Conceptualization, L.M. and H.W.; methodology, L.M.; validation, L.M., H.W. and C.Q.; formal analysis, H.Z.; investigation, X.Z.; resources, C.Q.; data curation, C.Q.; writing-original draft preparation, L.M.; writing—review \& editing, H.W.; supervision, H.W.; project administration, X.Z.; funding acquisition, C.Q.

Funding: This research was funded by the Natural Science Foundation Project [9164720026].

Acknowledgments: We thank the Appraisal Center for Environment \& Engineering, Ministry of Environmental Protection for providing EIA data. Sincere thanks also go to three anonymous reviewers for their very helpful comments and suggestions, which have helped us clarify and improve the manuscript. 
Conflicts of Interest: The authors declare no conflict of interest.

\section{References}

1. Dong, Z.R.; Sun, D.Y.; Zhao, J.Y.; Zhang, J. An holistic concept model for the structure and function of river ecosystems. Adv. Water Sci. 2010, 4, 550-559. (In Chinese)

2. Xie, J. Analysis of Multi-Scale Flood Series Alteration in the East River Basin. J. Water Resour. Res. 2012, 1, 370-374.

3. Grill, G.; Lehner, B.; Thieme, M.; Geenen, B.; Tickner, D.; Antonelli, F.; Babu, S.; Borrelli, P.; Cheng, L.; Crochetiere, H.; et al. Mapping the world's free-flowing rivers. Nature 2019, 569, 215. [PubMed]

4. MaGilligan, F.J.; Nislow, K.H. Changes in hydrologic regime by dams. Geomorphology 2005, 71, 61-78. [CrossRef]

5. Westwood, C.G.; England, J.; Dunbar, M.J.; Holmes, N.T.; Leeming, D.J.; Hammond, D. An approach to setting ecological flow thresholds for southern English chalk streams. Water Environ. J. 2017, 31, 528-536. [CrossRef]

6. Yang, Z.; Yang, K.; Hu, H.; Su, L. The cascade reservoirs multi-objective ecological operation optimization considering different ecological flow demand. Water Resour. Manag. 2019, 33, 207-228. [CrossRef]

7. Zhang, H.; Chang, J.; Gao, C.; Wu, H.; Wang, Y.; Lei, K.; Long, R.; Zhang, L. Cascade hydropower plants operation considering comprehensive ecological water demands. Energy Convers. Manag. 2019, 180, 119-133. [CrossRef]

8. Poff, N.L.; Olden, J.D.; Merritt, D.M.; Pepin, D.M. Homogenization of regional river dynamics by dams and global biodiversity implications. Proc. Natl. Acad. Sci. USA 2007, 104, 5732-5737. [CrossRef]

9. O’brien, G.C.; Dickens, C.; Hines, E.; Wepener, V.; Stassen, R.; Quayle, L.; Fouchy, K.; MacKenzie, J.; Graham, P.M.; Landis, W.G. A regional-scale ecological risk framework for environmental flow evaluations. Hydrol. Earth Syst. Sci. 2018, 22, 957-975.

10. Chen, Y.Q.D.; Yang, T.; Xu, C.Y.; Zhang, Q.; Chen, X.; Hao, Z.C. Hydrologic alteration along the Middle and Upper East River (Dongjiang) basin, South China: A visually enhanced mining on the results of RVA method. Stoch. Environ. Res. Risk Assess 2010, 24, 9-18. [CrossRef]

11. Poff, N.L.; Allan, J.D. Functional Organization of Stream Fish Assemblages in Relation to Hydrological Variability. Ecology 1995, 76, 606-627. [CrossRef]

12. Sagawa, S.; Kayaba, Y.; Tashiro, T. Changes in fish assemblage structure with variability of flow in two different channel types. Landsc. Ecol. Eng. 2007, 3, 119-130. [CrossRef]

13. Li, B.; Yu, Z.; Liang, Z.; Acharya, K. Hydrologic response of a high altitude glacierized basin in the central Tibetan Plateau. Glob. Planet. Change 2014, 118, 69-84.

14. Mims, M.C.; Olden, J.D. Fish assemblages respond to altered flow regimes via ecological filtering of life history strategies. Freshw. Biol. 2013, 58, 50-62.

15. Yang, Y.C.E.; Cai, X.M.; Herrick, E.E. Identification of hydrologic indicators related to fish diversity and abundance: A data mining approach for fish community analysis. Water Resour. Res. 2008, 44, W04412. [CrossRef]

16. Li, B.; Yu, Z.; Liang, Z.; Song, K.; Yan, W. Effects of climate variations and human activities on runoff in the Zoige Alpine wetland in the eastern edge of the Tibetan Plateau. J. Hydrol. Eng. 2014, 29, 1026-1035.

17. Horne, A.C.; Webb, J.A.; O’Donnell, E.; Arthington, A.H.; McClain, M.; Bond, N.; Acreman, M.; Hart, B.; Stewardson, M.J.; Richter, B.; et al. Research priorities to improve future environmental water outcomes. Front. Environ. Sci. 2017, 5, 89. [CrossRef]

18. Tharme, R.E. A global perspective on environmental flow assessment: Emerging trends in the development and application of environmental flow methodologies for rivers. River Res. Appl. 2003, 19, 397-441. [CrossRef]

19. Ping, Z.; Gao Linna, S.C. Integrated evaluation on aquatic ecosystems of main rivers and lakes in China. J. Hydraul. Eng. 2016, 47, 94-100.

20. Wang, L.; Mo, K.; Chen, Q.; Zhang, J.; Xia, J.; Lin, Y. Estimating ecological flows for fish overwintering in plain rivers using a method based on water temperature and critical water depth. Ecohydrol. 2019, 12, e2098.

21. Hua, Y.; Cui, B. Environmental flows and its satisfaction degree forecasting in the Yellow River. Ecol. Indic. 2018, 92, 207-220. [CrossRef] 
22. Chen, C.; Huang, J.; Chen, Q.; Zhang, J.; Li, Z.; Lin, Y. Assimilating multi-source data into a three-dimensional hydro-ecological dynamics model using Ensemble Kalman Filter. Environ. Model. Softw. 2019, 117, 188-199. [CrossRef]

23. Yang, S.M.; Shao, M.G.; Shen, X.P. Quantitative approach for calculating ecological water requirement of seasonal water-deficient rivers. J. Hydraul. Eng. 2005, 36, 1341-1346.

24. Yang, Z.; Sun, T.; Cui, B.; Chen, B.; Chen, G.; Chen, G. Environmental flow requirements for integrated water resources allocation in the Yellow River Basin, China. Commun. Nonlinear Sci. Numer. Simul. 2009, 14, 2469-2481. [CrossRef]

25. Li, J.; Xia, Z.; Wang, Y. Impact of the Three Gorges and Gezhouba Reservoirs on Ecohydrological Conditions for Sturgeon in the Yangtze River, China. J. Hydrol. Eng. 2013, 18, 1563-1570. [CrossRef]

26. Huang, F.; Xia, Z.; Li, F.; Guo, L.; Yang, F. Hydrological Changes of the Irtysh River and the Possible Causes. Water Resour. Manag. 2012, 26, 3195-3208. [CrossRef]

27. Chen, A.; Wen, J.; Wu, M.; Wang, P. Review of global and China's policies on fish passages. Hydrol. Res. 2019, 21, 708-721. [CrossRef]

28. Pan, Z.R.; Ruan, X.H. Spatio-temporal analysis of satisfactory degree of ecological water demand in Huaihe river basin. J. Hydraul. Eng. 2015, 3, 280-290.

29. Jia, B.; Zhang, Z.; Zhang, H.; Ci, L. On the current Research Status, Problems and Future Framework of Ecological and Environmental Water Use. Acta Ecol. Sin. 2002, 22, 1734-1740.

30. Lin, Q.; Li, H. Influence and guarantee on ecological basic flow of Weihe River from Baojixia water diversion. J. Arid Land Resour. Environ. 2010, 24, 114-119.

31. Xu, W.; Dong, Z.; Luo, X.; Fu, X.; Tan, J. Analysis of ecological flow in Luanhe River based on improved 7Q10 method. J. Hohai Univ. (Nat. Sci.) 2016, 44, 454-457.

32. Tennant, D.L. Instream flow regimens for fish, wildlife, recreation and related environmental resources. Fisheries 1976, 1, 6-10. [CrossRef]

33. Opperman, J.J.; Kendy, E.; Tharme, R.E.; Warner, A.T.; Barrios, E.; Richter, B.D. A three-level framework for assessing and implementing environmental flows. Front. Environ. Sci. 2018, 6, 76. [CrossRef]

34. Men, W.; Zhang, Y.; Zhang, N.; Cai, M.; Huang, Y. Concept, Characteristics, and Implementary Policy of Freshwater Ecosystem Function Management Regionalization. Res. Environ. Sci. 2013, 26, 465-471.

35. Sun, X.; Zhou, Q. Primary study of freshwater eco-regionalization in China. Acta Sci. Circumst. 2010, 30, 419-423.

36. GE, Q.; ZHAO, M.; ZHENG, J.; FANG, X. Study on division of the terrestrial system in China. Acta Geogr. Sin. 2002, 57, 515-522.

37. Ma, L.; Zhang, X.; Wang, H.; Qi, C. Characteristics and Practices of Ecological Flow in Rivers with Flow Reductions Due to Water Storage and Hydropower Projects in China. Water 2018, 10, 1091. [CrossRef]

38. Wu, M.; Chen, A. Practice on ecological flow and adaptive management of hydropower engineering projects in China from 2001 to 2015. Water Policy 2018, 20, 336-354. [CrossRef]

39. Chen, A.; Wu, M.; Chen, K.-Q.; Sun, Z.-Y.; Shen, C.; Wang, P.-Y.; Dou, Z.; Zhou, Z.; Wang, J. Main issues in research and practice of environmental protection for water conservancy and hydropower projects in China. Water Sci. Eng. 2016, 9, 312-323. [CrossRef]

40. Men, B.H.; Liu, C.M.; Xia, J.; Liu, S.X.; Ji, L.N. Estimating and evalufating on minimum ecological flow of Western Route Project of China's South-to-North Water Transfer Scheme for water exporting rivers. J. Soil Water Conserv. 2005, 5, 135-137.

41. Yi, Y.J.; Zhang, S.H. Review of aquatic species habitat simulation method and modelling. Sci. Sin. Technol. 2019, 49, 363-377. [CrossRef]

42. Yi, Y.; Sun, J.; Yang, Y.; Zhou, Y.; Tang, C.; Wang, X.; Yang, Z. Habitat suitability evaluation of a benthic macroinvertebrate community in a shallow lake. Ecol. Indic. 2018, 90, 451-459. [CrossRef]

43. Yi, Y.; Cheng, X.; Yang, Z.; Wieprecht, S.; Zhang, S.; Wu, Y. Evaluating the ecological influence of hydraulic projects: A review of aquatic habitat suitability models. Renew. Sustain. Energy Rev. 2017, 68, 748-762. [CrossRef]

44. Li, F.; Cai, Q.; Fu, X.; Liu, J. Construction of habitat suitability models (HSMs) for benthic macroinvertebrate and their applications to instream environmental flows: A case study in Xiangxi River of Three Gorges Reservoir region, China. Prog. Nat. Sci. 2009, 19, 359-367. [CrossRef]

45. Ban, X. Ecological flow requirement for Chinese sturgeon spawning habitat. J. Hydraul. Eng. 2011, 42, 47-55. 
46. Tonkin, J.D.; Poff, N.L.; Bond, N.R.; Horne, A.; Merritt, D.M.; Reynolds, L.V.; Olden, J.D.; Ruhi, A.; Lytle, D.A. Prepare river ecosystems for an uncertain future. Nature 2019, 570, 301. [CrossRef] [PubMed]

47. Li, C.; Kang, L. A new modified Tennant method with spatial-temporal variability. Water Resour. Manag. 2014, 28, 4911-4926. [CrossRef]

48. Chen, A.; Wu, M. Managing for Sustainability: The Development of Environmental Flows Implementation in China. Water 2019, 11, 433. [CrossRef]

(C) 2019 by the authors. Licensee MDPI, Basel, Switzerland. This article is an open access article distributed under the terms and conditions of the Creative Commons Attribution (CC BY) license (http://creativecommons.org/licenses/by/4.0/). 